\title{
Isolated ulnopalmar dislocation of the fifth carpometacarpal joint
}

\author{
Stefan Beekhuizen, Pieter Bas de Witte, Marijn Rutgers, David Ohanis
}

Orthopaedic Surgery, HagaZiekenhuis, The Hague, The Netherlands

\section{Correspondence to} Dr Marijn Rutgers, M.Rutgers@hagaziekenhuis.nl

Accepted 20 April 2018

\section{SUMMARY}

Dislocations of the carpometacarpal (CMC) joints are uncommon and are frequently missed on standard radiographs of the hand. Dislocations could be dorsal or palmar; dorsal dislocations are seen more frequently. Palmar dislocations can be either ulnopalmar or radiopalmar. Stable CMC dislocations could be successfully treated conservatively, while unstable dislocations are mostly treated operatively. The purpose of this report is to present a patient with an isolated ulnopalmar dislocation of the fifth CMC joint, satisfactorily treated with closed reduction and casting.

\section{BACKGROUND}

Dislocations of the carpometacarpal (CMC) joints are uncommon and are usually high-energy injuries with involvement of associated structures. Involvement of the ulnar nerve should be excluded by physical examination because of its proximity to the

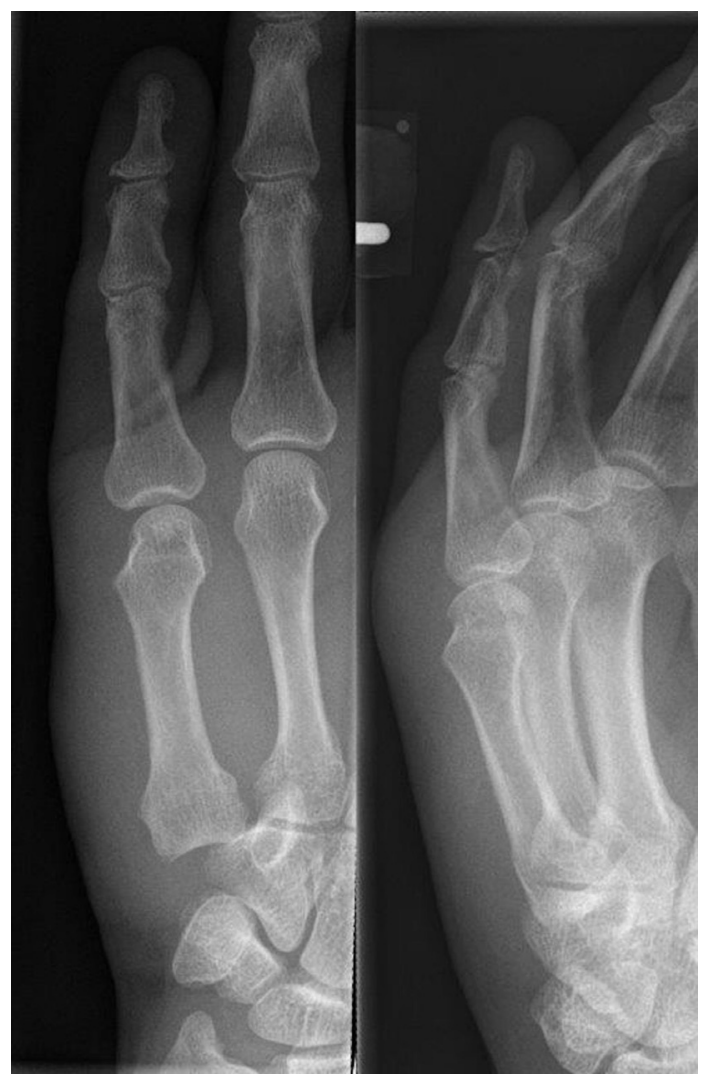

Figure 1 Anteroposterior and three-quarter X-rays showing an ulnopalmar dislocation of the fifth carpometacarpal joint.

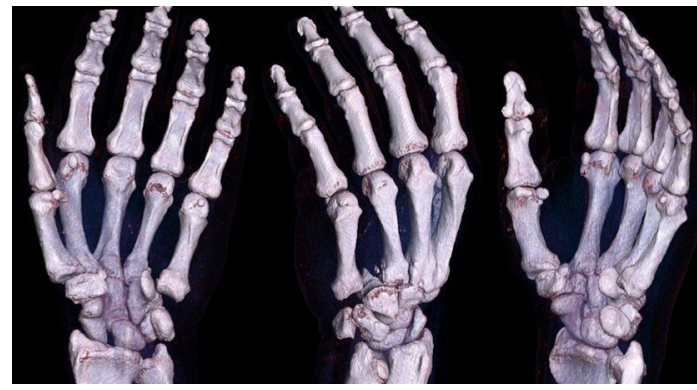

Figure 2 Three-dimensional reconstructions of the CT scan showing the ulnopalmar dislocations of the fifth ray.

fifth CMC joint. CMC dislocations are frequently missed on standard radiographs of the hand. ${ }^{1}$

Dislocations can be to the dorsal or palmar side, with dorsal dislocations observed more frequently. Palmar dislocations can be either ulnopalmar or radiopalmar. Only a few reports of isolated palmar dislocation of the fifth CMC joint have been described previously. Most of the reported cases are radiopalmar dislocations, and most of the reported ulnopalmar cases are surgically treated because of persistent instability. We report a case of ulnopalmar dislocation of the base of the fifth CMC joint, which was successfully treated with closed reduction and casting. There is very little literature available on ulnopalmar dislocations of the fifth ray, particularly about successful conservative treatment. The mechanism of the injury, clinical presentation and treatment options are discussed, with a review of the literature. The aim of this report is to increase awareness regarding CMC dislocations.

\section{CASE PRESENTATION}

A 67-year-old man was referred to the emergency department (ED) for evaluation of his painful and swollen left hand. He fell while playing tennis and suffered a hyperextension trauma of the fifth ray. According to the patient's story, the fifth ray showed signs of dislocation, observing a hyperextended position after trauma. He initially manipulated the finger himself, thereby restoring the little finger to almost neutral position. Physical examination at the ED showed severe swelling of the ulnodorsal aspect of the hand, and no clear dislocation or shortening was seen. Palpation showed tenderness at the base of the fifth metacarpal. Neurovascular exam showed no abnormalities.

The standard plain radiographs (figure 1) showed ulnopalmar dislocation of the fifth CMC joint, 


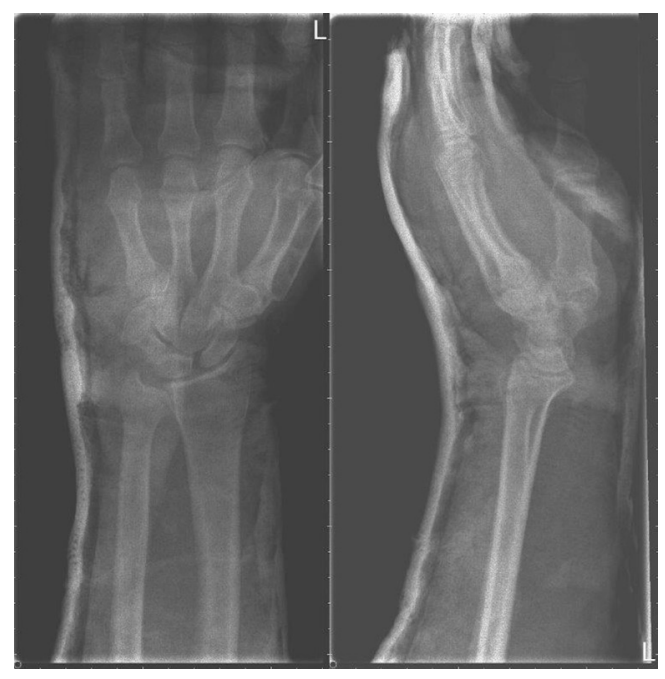

Figure 3 Anteroposterior and lateral X-rays (with plaster) showing successful reduction of the ulnopalmar dislocation.

without an evidential fracture. In accordance with the local trauma protocol and the trauma mechanism combined with severe swelling, an additional CT scan (figure 2) was performed, confirming the ulnopalmar dislocation and showing a very small avulsion fracture at the radial side of the fifth metacarpal base. Therefore, the injury was regarded as an isolated dislocation.

\section{TREATMENT}

Under local anaesthetics (Böhler's block, 1\% lidocaine), closed reduction was performed by longitudinal traction and direct pressure over the palmar base of the metacarpal. The reduction was stable and was confirmed by X-ray (figure 3 ).

The wrist and metacarpophalangeal joint of the fifth ray were immobilised in a cast for 4 weeks.

\section{OUTCOME AND FOLLOW-UP}

After 1 week, radiographs were repeated, still demonstrating a reduced fifth CMC dislocation. At follow-up after 4 weeks, the patient had no pain over the fifth CMC joint and went to the hand therapist to improve function after 4 weeks of immobilisation (figure 4). The patient had no functional impairment at final follow-up after 4 months.

\section{DISCUSSION}

Dislocation of the CMC joint is an uncommon injury, which accounts for less than $1 \%$ of all hand injuries. ${ }^{2} \mathrm{McWhorter}^{3}$ was

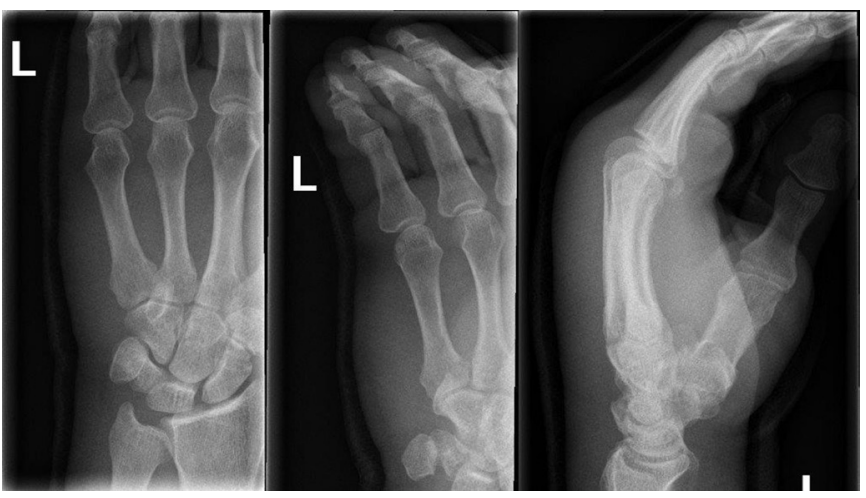

Figure 4 Anteroposterior, three-quarter and lateral X-rays with anatomical position of the fifth carpometacarpal joint at final follow-up after 4 weeks of immobilisation.

\section{Learning points}

- Dislocations can be to the dorsal or palmar side, with dorsal dislocations observed more frequently.

- The dislocation can easily be missed on standard anteroposterior and lateral radiographs; therefore, an additional $30^{\circ}$ pronated lateral view is advised in case of pain and swelling over the fifth carpometacarpal (CMC) joint in combination with adequate trauma.

- Involvement of the ulnar nerve should be excluded by physical examination because of its proximity to the fifth CMC joint.

- Stable CMC dislocations could be successfully treated conservatively, while unstable dislocations are mostly treated operatively.

the first who reported an isolated dislocation of the fifth CMC joint in 1918. Dorsal dislocations occur more commonly than palmar dislocations. They develop secondary to a force directed along the longitudinal axis of the fifth metacarpal shaft and in association with a fracture of the radial margin of the fifth metacarpal base in many but not all cases. In dorsal dislocations of the fifth CMC joint, the extensor carpi ulnaris pulls the fifth metacarpal proximally. In contrast, palmar dislocations can be classified into two groups according to the direction of displacement of the fifth metacarpal base: radial and ulnar. Radiopalmar dislocation is seen if all ligaments and tendons attached to the base of the fifth metacarpal are ruptured. This type occurs most frequently. If the pisometacarpal ligament and flexor carpi ulnaris tendon attachments remain intact, an ulnopalmar dislocation is seen. ${ }^{45}$

Fifth CMC dislocations are commonly represented by pain and swelling about the fifth metacarpal base, and frequently shortening of the fifth ray can be observed. Special attention must be given to examination of the ulnar nerve. The deep motor branch lies palmar to the fifth CMC joint as it courses around the hook of the hamate, and this makes it vulnerable to dorsal as well as palmar dislocations. ${ }^{6}$ In addition to standard anteroposterior (AP) and lateral radiographs, a $30^{\circ}$ pronated lateral view may provide a better view of the fifth CMC joint.

The treatment of palmar fifth CMC dislocations can be conservative as well as operative. Successful closed reduction and casting for ulnopalmar dislocation has been described by several authors. Also (open) reduction and K-wire fixation have been reported with good results. ${ }^{78}$ Instability is more frequent in case of radiopalmar dislocation, due to tearing of all ligament and tendon attachments of the fifth metacarpal base. Therefore radiopalmar dislocations are mostly treated surgically by percutaneous pinning or open reduction and internal fixation.

Ulnopalmar dislocation of the fifth CMC joint is uncommon and only a few cases are reported in the literature. The dislocation can easily be missed on standard AP and lateral radiographs; therefore, an additional $30^{\circ}$ pronated lateral view is advised in case of pain and swelling over the fifth CMC joint in combination with adequate trauma. Moreover, ulnopalmar dislocation is generally stable, and therefore closed reduction and casting should usually suffice. If instability persists, operative treatment with K-wire fixation can be considered.

Contributors SB: wrote the article. PBdW: treated the patient and corrected the article. MR: supervisor of the article. DO: wrote the article.

Funding The authors have not declared a specific grant for this research from any funding agency in the public, commercial or not-for-profit sectors. 
Competing interests None declared.

\section{Patient consent Obtained.}

Provenance and peer review Not commissioned; externally peer reviewed.

(C) BMJ Publishing Group Ltd (unless otherwise stated in the text of the article) 2018. All rights reserved. No commercial use is permitted unless otherwise expressly granted.

\section{REFERENCES}

1 Anjum R, Roy A, Farooque K, et al. An isolated pure dislocation of fifth carpometacarpal joint: case report and review of literature. J Orthop Case Rep 2017;7:14-16.

2 Domingo A, Font L, Saz L, et al. Isolated radial palmar dislocation of the fifth carpometacarpal joint with ulnar neuropathy associated: successful treatment with closed reduction and internal fixation. European J Orthopaedic Surgery \& Traumatology 2009;19:101-7.
3 McWhorter GL. Isolated and complete dislocation of the fifth carpometacarpal joint: open operation. Surg Clin Chic 1918;2:793-6.

4 Berg EE, Murphy DF. Ulnopalmar dislocation of the fifth carpometacarpal joint-successful closed reduction: review of the literature and anatomic reevaluation. J Hand Surg Am 1986;11:521-5.

5 Fisher MR, Rogers LF, Hendrix RW. A systematic approach to the diagnosis of carpometacarpal dislocations. Radiographics 1982;2:612-27.

6 O'Rourke PJ, Quinlan W. Fracture dislocation of the fifth metacarpal resulting in compression of the deep branch of the ulnar nerve. J Hand Surg Br 1993;18:190-1.

7 Tountas AA, Kwok JM. Isolated volar dislocation of the fifth carpometacarpal joint. Case report. Clin Orthop Relat Res 1984;187:172-5.

8 Nalebuff EA. Isolated anterior carpometacarpal dislocation of the fifth finger: classification and case report. J Trauma 1968;8:1119-23.

9 Ibn El Kadi K, Sbiyaa M, Alami B, et al. Isolated radial volar dislocation of the fifth carpometacarpal joint: a rare injury. Pan Afr Med J 2013;16:90.

Copyright 2018 BMJ Publishing Group. All rights reserved. For permission to reuse any of this content visit http://group.bmj.com/group/rights-licensing/permissions.

BMJ Case Report Fellows may re-use this article for personal use and teaching without any further permission.

Become a Fellow of BMJ Case Reports today and you can:

- Submit as many cases as you like

- Enjoy fast sympathetic peer review and rapid publication of accepted articles

- Access all the published articles

- Re-use any of the published material for personal use and teaching without further permission

For information on Institutional Fellowships contact consortiasales@bmjgroup.com

Visit casereports.bmj.com for more articles like this and to become a Fellow 